\title{
Causes of Behavioral Processes: An Interview with Mario A. Bunge
}

Causas de los Procesos Comportamentales: Un diálogo con Mario Bunge

\author{
Camilo Hurtado-Parrado* \\ University of Manitoba, Winnipeg, Canada \\ JAVIER Virues-Ortega \\ Toby L. MARTIN \\ St.Amant Research Centre, Winnipeg, \\ Manitoba, Canada \\ Flávia Julio \\ University of Manitoba, Winnipeg, Canada
}

Para citar este artículo. Hurtado-Parrado,. C., Virues-Ortega, J., Martin, T. L. \& Julio, F. (2011). Causes of Behavioral Processes: An interview with Mario A. Bunge, Universitas Psychologica, 10 (3), 965-972.

\footnotetext{
Correspondence concerning this article should be addressed to: Camilo Hurtado-Parrado, University of Manitoba, Psychology Department, 190 Dysart Road, MB R3T Winnipeg, Manitoba, Canada. Email: umhurtah@cc.umanitoba.ca

Research-ID: Hurtado-Parrado, G., G-3032-2011; Virues-Ortega, J., G-3648-2011; Julio, F., G-28632011.
}

\begin{abstract}
A B S T R A C T
Mario A. Bunge is one of the most prominent philosophers and humanists of our time. His vast record of publications has covered, among others, epistemology, ontology, ethics, philosophy of natural and social sciences, philosophy of technology, and philosophy of mind. A topic that intersects many of these areas and is recurrent in Bunge's work is causality. His analyses of the causal principle, and the redefinition of determinism into near-determinism have been applied to different philosophical issues that range from the causal role of neuronal functioning to the laws of social phenomena. Bunge has criticized functionalism, cognitivism, computationalism, behaviourism, and idealism in their attempt to explain human and non-human behaviour. This article results from an extensive interview held with Dr. Bunge in which we discussed a variety of conceptual issues related to the notions of causality and explanation in psychology.

Key words authors

Mario Bunge, causality, causation, explanation, psychology, philosophy, behavioural sciences.

Key words plus

Epistemology, ontology, history, interview.
\end{abstract}


Mario Augusto Bunge was born in Buenos Aires (Argentina) in September 21, 1919. In 1952 he obtained his doctorate degree in physico-mathematical sciences at the Universidad Nacional de La Plata and in 1963 decided to leave Argentina because of the convulsed political atmosphere of the time. After spending a few years as a visiting professor in United States, Mexico, and Germany, Dr. Bunge settled in Canada in 1966 and joined McGill University (Montreal). Since the beginning of his academic career, he has been a prolific scholar authoring over 50 books and hundreds of papers. And has been the recipient of many recognitions for his work. For instance, Dr. Bunge has obtained 16 honorary doctorates and four honorary professorships; he received the Prince of Asturias Award of social sciences (1982); and he became a fellow of the American Association for the Advancement of Science in 1984 and the Royal Society of Canada in 1992. Currently, Bunge is a Frothingham Professor Emeritus of Logics and Metaphysics at the department of Philosophy of McGill University.

Bunge has been interested in theoretical physics, epistemology, ontology, ethics, philosophy of science, philosophy of technology, and philosophy of mind. He has been a strong advocate of the axiomatization and realistic interpretation of theories in natural and social sciences, and a critic of materialistic views that reject qualitative aspects of consciousness. On the contrary, he argues that these qualitative aspects emerge as functions of brain activity. Bunge's philosophical stance has been labeled as critical realism and naturalistic ontology. His philosophical world is presented in depth in his eight-volume Treatise on Basic Philosophy (1974/1989) (Shook, 2005).

A topic that intercepts many of Bunge's areas of interest and has been developed considerably in his writings is causality (Bunge, 1958; Bunge $\&$ Bunge, 1998; Bunge, 2010a). Bunge's analyses of the notions of causation and causal principle, together with his redefinition of determinism (i.e., near-determinism), have been applied to epistemological and ontological issues in natural and social sciences that range from the causal role of neurological functioning to the laws of social phenomena.
On the basis of the psycho-neural identity (i.e., all cognitive and behavioural processes are neural processes), Bunge has criticised functionalism, cognitivism, computationalism, behaviourism, and idealism. In Bunge's perspective, causation in psychology, as in any other natural or social science, needs to be understood as an objective form of interdependence among real events in nature and society (Bunge, 1959).

The purpose of the present article is to elaborate Bunge's causal approach to specific behavioural processes. It results from an interview held with Dr. Bunge at his home in Montreal on October 16,2010 in which we discussed causality and explanation in psychology. Questions are presented in italics. The audio recording of the interview is available upon request. Dr. Bunge edited the final version of the present manuscript.

\section{Prevailing Notions of Causality in Psychology}

Since the early $20^{\text {th }}$ Century different variations of functionalism have been the prevailing approaches to causation in psychology. Cognitive psychology resorts to specific psychological functions and processes to account for human behaviours such as attention, selfesteem, or cognitive dissonance, while more behaviouristic-oriented approaches resort to specific behavioural functions like conditioning or reinforcement. It is not clear, however, how psychological hypotheses would expand functionalist explanations unless we develop some kind of multi-level accounts in which psychological explanations are paralleled by the operation of discrete brain areas or neuronal assemblies. Nevertheless, it is unlikely that cognitive processes or structures identified through statistical or inductive methods (e.g., the central executive component of memory) could be paralleled by discrete neural processes or structures. To what extent can a psychobiological approach rely on earlier traditions?

Mario Bunge (MB): In my view, neither behaviourists nor functionalists can explain anything. Why? Because causal explanation involves causes and causes are events in material things. To say that this state was followed by this other state is not 
to give a causal explanation. If you, on the other hand, make reference to material things such as the brain you can hope to explain. For instance, if you say this person got frightened and as a consequence he fled -a functionalist statement- you are not explaining anything. It's pure description. If on the other hand, we say that the person saw a scene that frightened him causing him to run away; then, what do we mean by "frightened"? His visual system signalled to the cortex which identified that scene as frightening, and the cortex sent a signal to the amygdala, which in turn activated the motor strip, so he ran away. That is a causal chain. That happens within a material system, the nervous system. In that case you give a causal explanation. Functionalists cannot explain anything. The difference between functionalists and behaviourists is that functionalists involve the use of mentalist concepts or constructs that behaviourists refuse. That is the only difference, but neither of them can explain. The advantage of functionalists is that they admit or recognize the existence of mental processes.

Would you say that the most elements in that causal chain are identified, the most comprehensive the psychobiological explanation would be?

MB: Yes, the deeper the explanation would be. Moreover, based on an explanation tied to a material system you can really act. For instance, the clinical psychologist can teach his patient, a young patient in particular, to master or dominate his anxieties, his phobias and so on and so forth, because he can combine various approaches. For example, he can apply purely cognitive psychology in combination with a pill, an anxiolytic pill, and he can re-train the patient. A clinical psychologist can re-educate and a biological psychologist can act directly on the nervous system, he can change, let's say, the density of neurotransmitters. Accordingly, the two combined can be effective, can do something to correct certain types of mental disorders. Also the behaviourist can do something, if they believe in learning. But they are limited by the lack of theory. They can correct bed-wetting or self-injury, but they cannot do much more than that. They cannot do much about anxiety disorders or depression.

\section{Environmental and Genetic Causes}

Traditionally, the nature/nurture dilemma has been posed in exclusive terms. However, a more current approach to behavioural genetics this debate would be rendered irrelevant. For instance, when learning is taking place, specific genes are activated in the cell, in the cell's genetic material. Additionally, there is also evidence to suggest that while specific behavioural performance may not be inherited, more molecular components of, let's say, learning (e.g., preference to certain types of stimulation) can in fact be inherited. What needs to change in psychology so this piece of the causal process is integrated in psychological theories?

MB: Well, I think that the debate in nature/ nurture remains only among the genetic determinists; that is, people who think that genes are the exclusive causal source. There are still a few of these people, but not among psychologists. Among so-called evolutionary psychologists, perhaps. But ordinary psychologists don't believe in that dichotomy. Donald Hebb used to say it is like asking: "What is the correct measure of a soccer field? the length, or the width?" It is the area! You have to multiply the length by the width. Both nature and nurture are involved; particularly now that we know about epigenetic learning. We know something about the chemical rules of epigenetic processes, namely methylation of the genome, of the DNA. That can be inherited. So we now know that some learning can be inherited. We know that the chemical basis is methylation. Certain environmental stimuli can produce this chemical process which in turn is inheritable. This is a case where nature and nurture unite. I think that the debate has been reopened in the sense that now more than ever we realize that we have to take both together.

\section{Historical Causes}

You have suggested that spontaneous neural activity is a datum opposing the view that external efficient causes may be the exclusive causes of human beha- 
viour. Nevertheless, there are very few authors that would defend that merely immediate external causes can explain completely any form of complex human behaviour. Others would argue that the individual is responding not only to the current environment, but also to his past environment, which is somehow encrypted in the individual's brain. How would you evaluate this approach to characterize proper causes of complex human behaviour?

MB: Well, you are taking the classical approach, but this is not the most popular, which is the computationalist approach. Computationalists suggest that the mind or the brain is a computer. So everything it does, it does because it has been programmed. Moreover, most programs are innate, and if your activities and your mental processes have been programmed, then they are not spontaneous. You have been programmed to do that. It's what someone has called the "stupidity theory of mental behaviours," meaning that we are automata. There is no intelligence, there is no free will, there is no spontaneity; we are utterly at the mercy of either the environment or our genome (our programs). We are utterly stupid. This is the most popular approach. Similarly, we are at the mercy of instincts in the case of psychoanalysis, or at the mercy of the environment in the case of behaviourism. How do you explain free will? They will tell you that there is no such thing. If you are a scientist you cannot believe in free will. Well, it is a fact, an everyday experience: I do certain things because I want to, and so I am self-programmed. I invent my programs. Computationalists are not interested in free will. As a consequence, they leave free will in the hands of theologians or in the hands of idealist philosophers when it is a very interesting problem for cognitive neuroscientists. One of the very few Argentinian cognitive neuroscientists, Facundo Manes, is working precisely on that: the biology of free will (Bekinschtein \& Manes, 2008). Selfstarted behaviour or self-programming, if you wish. So it is not quite true that most psychologists will admit spontaneity. The computationalists deny it, if not explicitly at least tacitly. It is fashionable to say "he is programmed to do this", "the brain programs that," or "the programs are doing this or that". And there are computer models of a number of mental activities. But again, the computationalists are not interested in the nervous tissue.

Moreover, computers are not supposed to feel any emotions. We do not pay to buy emotional machines that will be subject to depression, exhilaration, or that will behave irrationally. We want our machines to follow rational programs. So the whole computational psychology leaves emotions aside. Consequently, it cannot explain why some people are very emotional about their mental activities or why scientists are passionate about their research. If you are programmed you cannot be passionate about anything. We know social emotions since the times of Adam Smith. Empathy and sympathy are very important social emotions. And you cannot explain social life without taking emotions into account; however, the current fashion is, at least among the computationalists, to leave emotions aside.

What you are saying is that emotions are not integrated into a wider psychological theory?

MB: Yes, the same happens with most philosophers of mind. For instance, John Searle will tell you that the brain causes the mind (Searle, 2004). This is complete nonsense. It is like saying that legs cause walking. A thing cannot cause its function, its processes. A very famous philosopher of mind Jaegwon Kim says that what is characteristic of pain is that it hurts (e.g., Kim, 1996). Again, it is like saying that motion moves. Complete nonsense. Your tooth hurts. It is not the tooth pain that hurts you. Actually, pain is something that we will feel in the brain. Although we can locate the source somewhere else, the pain takes place in the brain.

Let's consider the historical component of behavioural causation that we mentioned in an earlier question. Historical causes are difficult to explore through scientific methods because crucial data is no longer available. Conversely, scientific research is to a great extent fuelled by immediately contiguous events. As a result, 
behaviour that is caused or facilitated by remote events can be hardly submitted to such analysis. How can we study effectively this category of causes?

MB: Well it is true that in the elementary definition of causation you take into account point events that occupy no time lapse. But as a matter of fact an event is just a point in a process. You deal with processes all the time. You cannot explain the current behaviour of someone without taking into account his past, education, experiences, and so on. You can take those for granted when analyzing simple causal processes. In a more elaborated definition of causation you can explore the presence of specific endpoints in the presence or absence of a given history. In any case, it is true that the past is no longer here; however, the past leaves traces. Traces are everywhere. Some of them are in us.

Finding out what those traces were lead us again to the problem of indicators, and also to the so-called inverse problems. When you approach a patient as a clinical psychologist you are facing a black box. You can see only certain terminals and outputs of that black box (verbal behaviour outputs). And you try to imagine what the inputs were and what caused a given behaviour. In other words, you imagine the inner mechanism that transduces inputs into outputs. Therefore, the clinical psychologist, just as the physician and the engineer, faces inverse problems. In an inverse problem you are given the result and you have to try out and imagine what the initial causes were.

Engineers frequently deal with inverse problems. An engineer is told to design a machine that will produce a given desired effect. He has to imagine a mechanism that, when subjected to certain inputs (e.g., pressing a button) will produce a desired effect. Philosophers have not faced inverse problems. A couple of years ago I submitted a paper on inverse problems to a number of journals and all of them rejected it. The referees have never heard about inverse problems. Still, this is one of the most interesting and difficult of all problems. Even mathematicians have started looking at inverse problems in a systematic way only over the past 30 years.

\section{Methodology and Causation}

Causation in psychology may be closely related to the idea of identifying unitary events susceptible of explanation.

MB: They can be processes, not events. For instance, learning is a process not an event. Of course in some elementary cases such as when a dog learns about a hot plate in just one trial, the animal does not need a second experience. The animal will learn for life that a hot plates burn. But learning more complex tricks, for instance, fetching, will take longer. German sheppards can learn up to some 200 commands or more. It is a long apprenticeship, it takes years. Actually, there are obedience schools that may train an animal for a couple of years. Hence, no just point events but processes.

So specific units are not needed? To identify causes we need discrete events to be the target of our analysis (e.g., a unit of learning or a unit of behaviour).

MB: Those are idealizations, there are not such units of behaviour. Behaviour is always a process. If the process is very short you could analyze it as an event but it is actually a process. Behaviour occurs in the course of time. Processes and changes in general, can only occur in material things, not in ideal ones. Conversely, immaterial souls cannot learn.

Experimental approaches in psychology have emphasized either the repeatability of psychological phenomena (within-an-individual or within-subject experimental studies) or its replicability (across individuals or groupbased studies) in order to achieve consistent findings. Both approaches, among others, suffer from strong shortcomings. In single-subject studies, variation of the behaviour over time due to learning or practice is a clear limitation; conversely, excessive inter-individual variation is a weaknesses of group-based experimental designs. To what extent these shortcomings limit the ability of psychological theories to generate satisfactory explanations?

$M B$ : It is a clear limit. It is an objective limitation. Hebb used to make fun of this: If you take two 
identical organisms or animals then subject them to exactly the same conditions, they will behave in completely different ways. Yes, you will have to try to freeze certain variables. Well, you do that forcefully when you put a monkey in a seat and fix its head to force the animal to look in a certain direction. And of course, you use an acoustically isolated room with constant illumination and so forth, but these are obviously very artificial conditions. So, you have to try to combine these laboratory approaches with a naturalistic approach. For instant, Frans de Waal had done many things combining these two approaches. He has monkeys sit in cages but he has also monkeys and apes jumping around in a semi-natural environment. This way, he had been able to learn a lot about the social behaviour of apes and monkeys; for instance, the question whether there is altruism in monkeys or in apes (e.g., de Waal, Leimgruber \& Greenberg, 2008).

In a recent paper you mentioned that a useful procedure for evaluating the scientific character of a discipline is to assess separately its substantive hypotheses and methods (Bunge, 2010b). Following this procedure, you consider that Gestalt school, behaviourism, and computational psychology or cognitive psychology had wrong substantive hypotheses but proper method. In which sense can the method of these approaches be considered appropriate?

MB: Well, behaviourists introduced experimental rigor into psychology, or among those who were experimentally rigorous. Regarding the Gestalt school, they were also methodologically correct. Alternatively, computationalists were not. In fact, I do not think computationalists are interested in experiments; they are theorists. The behaviourists in particular, they controlled experimental variables, but they were superficial, and there was no need for such methodological sophistication where they had practically no hypotheses. Complicated hypotheses require complicated experimental procedures. But if your hypotheses are just relations between stimuli and responses, all you have to do is to control stimuli and responses, which is not very much. You are not controlling the state of the animal.
Let's go back to the causal processes. Let's think about molar and molecular explanations. Some classical psychology theoreticians have suggested that psychological models may only provide molar explanations (Hull, 1943). This claim may be related to same extent to the magnitude of the inter-and intra-individual variability found in psychological events. As a result, molar explanations may have a lower theoretical profile and generate less useful explanations and predictions. What approaches to theorization and methodology may facilitate a better account of variability and, therefore, open a path for more molecular theories in psychology?

MB: That depends on how deep you want to go. For instance, you can explain certain linguistic disorders taking into account just small regions of the left part of the brain, in the case of left handed people. More complex processes require much wider regions of the brain. So that depends really on the volume of the brain that is involved in that process. For instance, take dyslexia which appears to be predominantly a male disorder. Since women use both hemispheres when they speak, while men only use the left, women have apparently a much better control. As a result, girls do better in reading and writing at school than boys. Moreover, dyslexia seems to be a genetic disorder, apparently it is inheritable. Therefore, you have to refer to micro processes at a genetic level.

\section{Near-Determinism}

Would you define yourself as a determinist?

MB: No, I modified the concept of determinism. I think that quantic mechanics have told us that we have to take chance seriously. That is why in my book on causality I introduced the concept of near-determinism (Bunge, 1959). I defined neardeterminism based on two necessary and sufficient conditions: first, everything occurs according to law, and second, nothing comes out of nothing. But those laws can be probabilistic or can be causal, or a combination of the two. In my analysis I claimed that this combination occurs in quantic mechanics where you calculate, for instance, the probability that certain potential will cause a deviation of a 
particle within a certain solid angle. Therefore, you combine causation with chance.

This approach seems to be relevant to psychology.

MB: Yes, it is. In order to perceive, in order to remember, to make decisions, and so on, you need trillions of neurons, entire cell assemblies. It is possible that a single neuron can detect a stimulus, let's say a vertical or horizontal line, but not perceive it. Hubel and Wiesel (1959) investigated that topic long ago, the so-called "feature detectors." Nevertheless, they are detectors, and sensation and perception are different things. In order to be able to perceive something as a line and not simply react to the stimulus you need trillions of neurons.

It is interesting that near-determinism may affect how precise psychological explanations may get to be in the future; they may reach a ceiling beyond which progress may not be possible.

MB: We had hardly started. The most sophisticated psychological models now are computational models. In my view they are completely wrong since they don't take emotions or spontaneity into account. Computational models are based on computers not humans. They are also very specialized and they do not take into account biological processes. I think we have to start again. Some 40 or 50 years ago there were a number of neuroscientific models that were given up because most of them were far too simplistic. They assumed that neurons are either on or off, that they fired instantaneously, and so on. Neuroscientists did not take into account processes, the fact that nervous transmission is gradual and so forth. For instance, the McCulloch model (McCulloch \& Pitts, 1943) and other similar models have been completely forgotten already because they are not biological. They are not realistic. As a result, I think we have to start again.

A fundamental problem lays on the education of psychologists. They don't learn mathematics; only statistics. The kinds of mathematics that could best be used, at a preliminary level, which are qualitative mathematics, abstract algebra and things like that, are not taught at psychology schools. The mathematics that psychologists learn is either statistics or calculus. But the calculus is far too complex. In consequence, we shall start at a more primitive level. Every once in a while you have mathematicians that do mathematical psychology. As a matter of fact, there is a Journal of Mathematical Psychology, but the models that are public in that journal are unrealistic too. Once more, mathematical psychologists don't take neurophysiology into account. Instead, they deal only with highly elaborated processes (e.g., decision processes), but they leave aside elementary processes such as learning, memory, attention and so on. For instance, what is the difference between seeing and looking? Or the difference between hearing and listening? We need to know more about that; definitely there are too few papers about these elementary questions.

\section{References}

Bekinschtein, T. A., \& Manes, F. F. (2008). Neurobiology of consciousness. Vertex, 19, 35-44.

Bräuer, J., Call, J., \& Tomasello, M. (2009). Are apes inequity averse? New data on the token-exchange paradigm. American Journal of Primatology, 71, 175-181.

Bunge, M. (1959). Causality. The place of the causal principle in modern science. Cambridge: Harvard University Press.

Bunge, M. (1967). Foundations of physics. Berlin-Heidelberg-New York: Springer-Verlag.

Bunge, M. (1974-1989). Treatise on basic philosophy (Vols. 1-8). New York: Springer.

Bunge, M. (2010a). Matter and Mind: A philosophical inquiry. Dordrecht, the Netherlands: Springer Verlag.

Bunge, M. (2010b). Knowledge: Genuine and Bogus. Science $\mathbb{E}$ Education. Advanced online publication. DOI:10.1007/s11191-009-9225-3.

Bunge, M. \& Bunge, M. (1998). Philosophy of science: From explanation to justification (Vol. 2). New Brunswick, NJ: Transaction Publishers.

Damasio, A. (1995). Descartes' error: Emotion, reason and the human brain. New York: Penguin. 
De Waal, F. B. M., Leimgruber, K. \& Greenberg, A. R. (2008). Giving is self-rewarding for monkeys. Proceedings of the National Academy of Sciences of the United States of America, 105, 13685-13689. DOI:10.1073/pnas.0807060105

Hubel, D. H. \& Wiesel, T. N. (1959). Receptive fields of single neurons in the cat's striate cortex. Journal of Physiology, 148, 574-591.

Hull, C. L. (1943). Principles of behavior. New York: Appleton-Century-Crofts.
Kim, J. (1996). Philosophy of mind. Oxford: West View Press.

McCulloch, W. S. \& Pitts, W. (1943). A logical calculus of the ideas immanent in nervous activity. Bulletin of Mathematical Biophysics, 5, 115-133.

Searle, J. R. (2004). Mind: A brief introduction. New York: Oxford University Press.

Shook, J. R. (2005). The Dictionary of Modern American Philosophers (e-reference ed.). New York: Oxford University Press. 